\title{
Drosophilidae feeding on animals and the inherent mystery of their parasitism
}

Jan Máca ${ }^{1}$ and Domenico Otranto ${ }^{2^{*}}$

\begin{abstract}
Insect evolution, from a free to a parasitic lifestyle, took eons under the pressure of a plethora of ecological and environmental drivers in different habitats, resulting in varying degrees of interactions with their hosts. Most Drosophilidae are known to be adapted to feeding on substrates rich in bacteria, yeasts and other microfungi. Some of them, mainly those in the Steganinae subfamily, display a singular behaviour, feeding on animal tissues or secretions. This behaviour may represent an evolving tendency towards parasitism. Indeed, while the predatory attitude is typical for the larval stages of a great proportion of flies within this subfamily, adult males of the genera Amiota, Apsiphortica and Phortica display a clearly zoophilic attitude, feeding on the lachrymal secretions of living mammals (also referred as to lachryphagy). Ultimately, some of these lachryphagous species act as vectors and intermediate hosts for the spirurid nematode Thelazia callipaeda, which parasitizes the eyes of domestic and wild carnivores and also humans. Here we review the scientific information available and provide an opinion on the roots of their evolution towards the parasitic behaviour. The distribution of T. callipaeda and its host affiliation is also discussed and future trends in the study of the ecology of Steganinae are outlined.
\end{abstract}

Keywords: Drosophilidae, Steganinae, zoophagy, parasitism, lachryphagy, Phortica variegata, Thelazia callipaeda

\section{Introduction}

Initial stages of parasitism in insects

Insects and arachnids of medical and veterinary concern (e.g., mosquitoes, sand flies, stable flies, black flies, and ticks) have been studied extensively over the centuries, primarily because of the effect of their parasitic feeding habits on many species of domestic and wild animals, and humans. Indeed, these arthropods affect the health, welfare and production of animals through the transmission of disease-causing pathogens or just through biting them, therefore causing blood loss, allergic reactions, and/or nuisance and disturbance [1]. Evolution of arthropods, from a free to a parasitic lifestyle, took eons under the pressure of a wide range of ecological and environmental drivers, resulting in varying degrees of interactions with their hosts, e.g. from virtually necrophagous larvae, occasionally also causing facultative myiasis, to obligate parasitism. However, scientific information on the insect taxa that evolved only partial

\footnotetext{
* Correspondence: domenico.otranto@uniba.it

${ }^{2}$ Department of Veterinary Medicine, University of Bari, 70010, Valenzano, Bari, Italy

Full list of author information is available at the end of the article
}

parasitic interactions with their hosts, is scant [2,3], and it puts them in a group of organisms of an as yet undefined parasitic status. For example, most Drosophilidae are known to be adapted to feeding on substrates rich in bacteria, yeasts and other fungi (e.g., decaying or fermenting fruit) [3]. However, some of them display a different feeding behaviour as they may feed on animal tissues or secretions (hereinafter referred as to "zoophagy"), therefore being of medical and veterinary importance. This particular behaviour may represent an evolving step towards parasitism. Indeed, there is still paucity of information on the natural history of these drosophilids, and great part of knowledge available to date derives from incidental findings from studies from the $19^{\text {th }}$ century [3]. The still limited entomological data on these insects is partly due to the difficulties in breeding these species under laboratory conditions [4]. Here we review the scientific information available and provide an opinion about the main drivers, which might have affected some drosophilid genera of the subfamily Steganinae towards parasitic behaviour.
C Biomed Central

(c) 2014 Maca and Otranto; licensee BioMed Central Ltd. This is an Open Access article distributed under the terms of the Creative Commons Attribution License (http://creativecommons.org/licenses/by/4.0), which permits unrestricted use, distribution, and reproduction in any medium, provided the original work is properly credited. The Creative Commons Public Domain Dedication waiver (http://creativecommons.org/publicdomain/zero/1.0/) applies to the data made available in this article, unless otherwise stated. 


\section{Review}

\section{Zoophagy in Drosophilidae}

Drosophila melanogaster (Diptera, Drosophilidae), the "vinegar fly", is the quintessential member of this large family of insects, having had an enormous impact on various fields of science over the last century. Indeed, studies using this insect as a laboratory model have enabled great achievements in the field of developmental sciences (e.g. genetics, heredity, evolution, biochemistry, molecular biology, and cell biology) [5] as well as in applied disciplines such as neuroscience [6], the study of intellectual disability [7], metabolic disorders (e.g., obesity) [8] and oncology [9]. The reasons for the success of these tiny flies in science are related to their tolerance to environmental conditions, ease of rearing, short reproduction times, large numbers of offspring and the occurrence of several types of hereditary variations within a small genome size (i.e., four pairs of chromosomes). With the exception of this iconic species, as many as ca. 4,200 known species are included in the Drosophilidae family $[10,11]$, displaying wide variations in morphology, behaviour, biology and ecology [12].

Two subfamilies are ranked in this family, namely the Drosophilinae, which at present includes 3,182 described species, and the less well-represented Steganinae, with 1,008 species [10]. Morphological characteristics of these subfamilies have been described in $[13,14]$. In Drosophilinae, zoophagous and/or commensal behaviour is restricted to larvae of a few scattered clades, classified at present as parts of the genera Drosophila (mainly simulivora group species), Zygothrica (1 species), Scaptomyza (subgenus Titanochaeta) and Lissocephala (1 species); altogether $\mathrm{ca}$. 20 species [12]. Most other Drosophilinae are generally micromycetophagous (Sacharomycetales are clearly preferred substrates), although mycetophagy, saprophagy and phytophagy are typical for some genera or species groups [3].

As concerns the subfamily Steganinae, data based on cladistic and phylogenetic analyses showed that some of their morphological characters are related to numerous morphological convergences [13,14]. Predatory behaviour is typical for the larval stages of a great proportion of flies within this subfamily, although sometimes only in the initial stages (i.e., commensals that may ultimately kill their host). Members of the genera Acletoxenus and Rhinoleucophenga, as well as some species of Cacoxenus (subg. Gitonides) and Leucophenga, feed on Homoptera. Meanwhile, Hymenoptera (Apoidea) are hosts/prey of Cacoxenus s.str. and of some C. (Gitonides) species, and Coleoptera (Scolytidae) are prey of Phortica xyleboriphaga [12]. The substrates from which other Steganinae larvae have been bred include mostly fungi and decaying herbs or parts of logs. At least some of these may be zoophagous or zoosaprophagous; this hypothesis, proposed for Stegana coleoptrata 100 years ago [15], has been widely neglected. The adult stages of various Steganinae (Figures 1,2) display a necrophilic attitude, as inferred by the relatively high attractiveness of protein traps containing dead mice to some genera of Steganinae (Leucophenga, Gitona, Phortica, Amiota) [16]. More importantly, some members of Steganinae display a clearly zoophilic tendency, feeding on mammals. For example, the adults of many species within the genera Amiota, Apsiphortica and Phortica may feed not only on fermenting substrates, but also on the lachrymal secretions of mammals (Figure 3). This zoophilic attitude is also referred as to lachryphagy. Since the first description of $P$. variegata imbibing the lachrymal secretions of humans, thus causing annoyance [17], many authors observed this phenomenon [18], coupled with attractiveness to animal perspiration (Additional file 1: video).

\section{Peculiar behaviour of lachryphagous Steganinae}

Lachryphagy has been identified for many species of Amiota and Phortica - subcosmopolitan, moderately common and moderately species-rich genera, each comprising about 130 described species [10]. However lachryphagy is unknown in the Allophortica (subgenus of Phortica) comprising five described species. Flies belonging to the genera Amiota and Phortica are distributed mostly across temperate to tropical forests and lacking in arid biotopes such as those of central Asia. Conversely, the third lachryphagous genus, Apsiphortica, includes only six rare species in Africa and Southeast Asia. Finally, there are also single observations of lachryphagy in the genera Gitona [19], Paraleucophenga [2] and Apenthecia (S. Prigent, personal communication), but confirmatory studies are needed. Although the subdivision of Steganinae has not been clearly resolved, it appears that lachryphagous genera do not represent a monophyletic group [14,20]. On the other hand, the genus Phortica, of which adult flies display a marked lachryphagy, was recently separated from

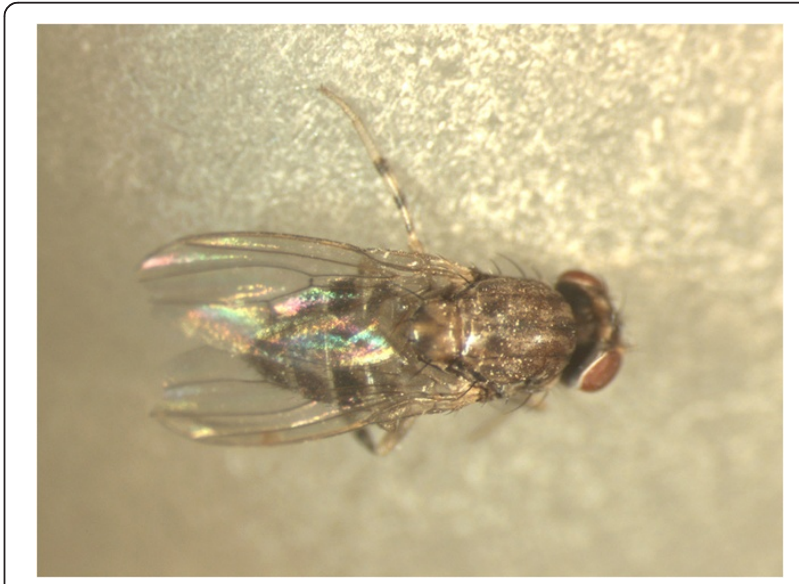

Figure 1 Phortica variegata. Adult of Phortica variegata (Fallén), as representative of the subgenus Phortica s. str., containing more than 80 species known species with a similar appearance. 


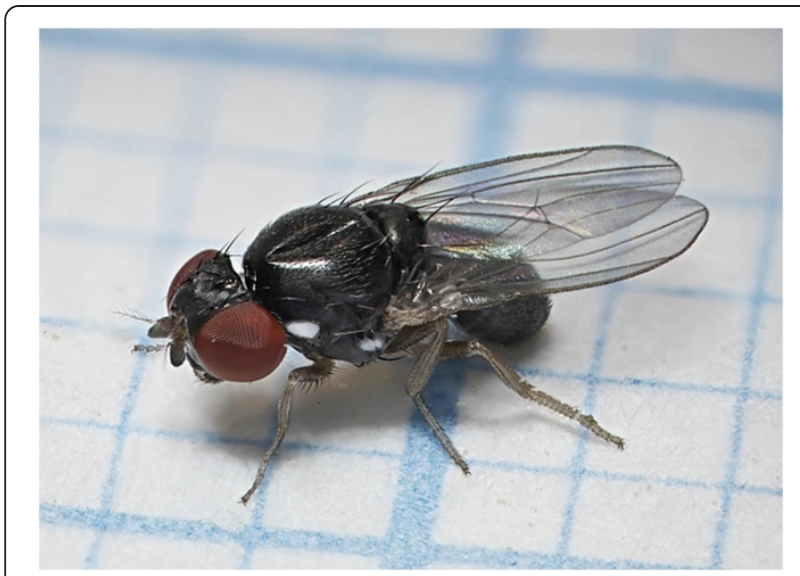

Figure 2 Amiota filipes. Adult of Amiota filipes Máca. Most of the Amiota species are black or brown with silvery spots on face, postpronotum and katepisternum. Original, courtnesy K. Nielsen.

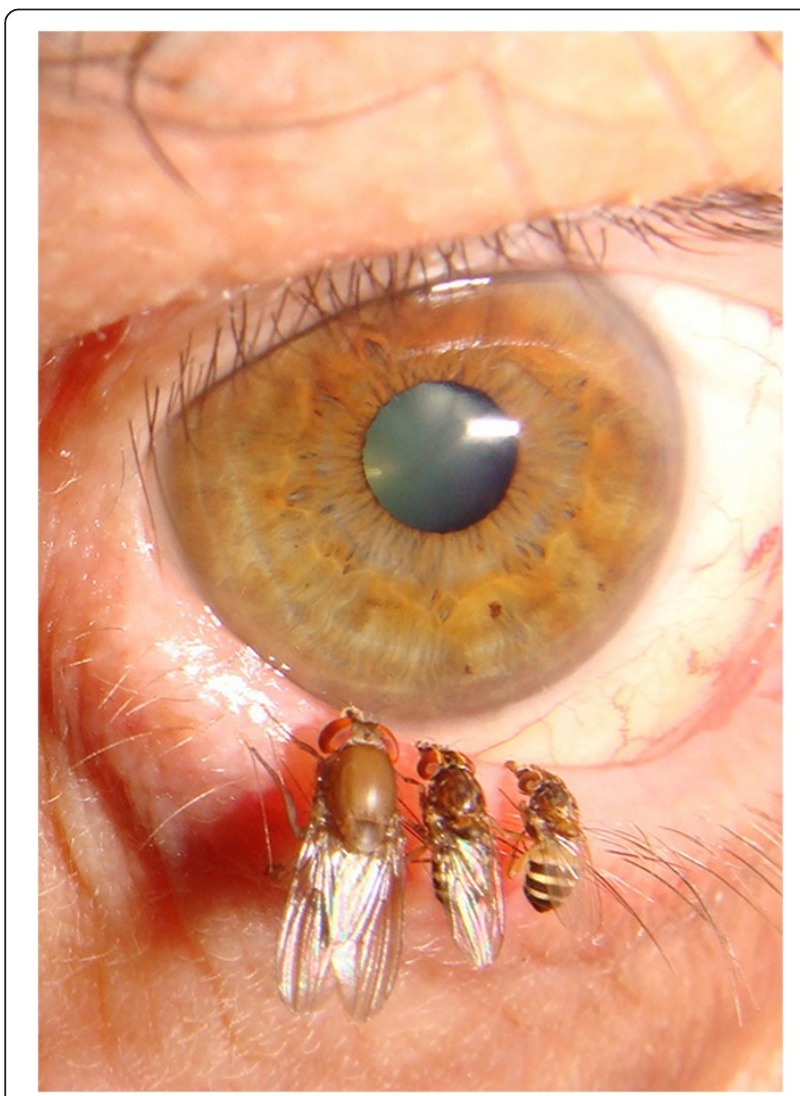

Figure 3 Drosophilids at human eye in Thailand. Three fruit flies (Drosophilidae) sipping tears from the human eye. Left: female Apsiphortica longiciliata Cao \& Chen (females are very rarely lachryphagous); center: male Phortica pseudotau (Toda \& Peng); right: male Phortica sp. (Photo H. Bänziger, from Bänziger et al., 2009 [2]).
Amiota and its monophyly was confirmed by cladistic analyses [21-23]. Studies of the feeding habits of Phortica variegata confirmed previous observations, showing that whilst females prevailed on the fruit bait (male:female ratio 1:3.8), lachryphagous behaviour is exclusively by males [24]. Similar observations, although on smaller scale, exist in a number of other species of relevant genera. This behaviour is opposite to that of blood-feeding insects showing sex-related preferences (e.g., mosquitoes, ceratopogonids, sand flies, black flies and tabanids), where only adult females are haematophagous [25], with the remarkable exception of the hematophagous males of the genus Calyptra (Lepidoptera).

Males of $P$. variegata hover around animals and humans, possibly resting close to their eyes, imbibing tears (i.e., lachryphagy) and, occasionally, also sucking their perspiration. When trying to access their eyes, this behaviour ultimately causes a nuisance to animals [26]. Such behaviour of males is a remarkable characteristic of the abovementioned lachryphagous Steganinae (Figure 3), similarly to the members of the family Cryptochetidae (genus Cryptochetum), representing a sister-group of Drosophilidae [27]. Importantly, in other lachryphagous Diptera (some Muscidae, Fanniidae, Chloropidae and Paraleucopidae) females are prevalent, while the restriction of the lachryphagous behaviour to males is a rule in various Lepidoptera (except the moths Arcyophora and Lobocraspis, where both sexes are involved) [2]

Drosophilidae, and some other lachryphagous Diptera, can only feed on tears and perspiration, Paraleucopis mexicana can also intake blood from fresh wounds and some Chloropidae (e.g., Liohippelates spp.) cause direct injury except lachryphagy: they developed morphological adaptations of their mouthparts to reopen wounds of their hosts [28]. This is not the only pathway to parasitism: facultative bloodsucking moths of the genus Calyptra evolved from the fruit-piercing ancestors [29,30], various necrophagous flies may cause myiasis. However, lachryphagous insects feed on living animals, which makes the boundary between lachryphagy and true parasitism not obvious, and thus we tentatively consider lachryphagous behaviour as parasitical in the broad sense.

\section{The role of some Steganinae as vectors of helminths}

Some of the lachryphagous Steganinae are known as vectors and intermediate hosts for the spirurid Thelazia callipaeda (Spirurida, Thelaziidae), which parasitizes the eyes of domestic and wild carnivores and some lagomorphs (see below) [31]. While feeding on animal tears, male flies have contact with the first larval stages of $T$. callipaeda and act as their intermediate hosts. In comparison to the relative species richness of lachryphagous Steganinae, strikingly few species have been confirmed as vectors of $T$. callipaeda larvae. This spirurid, known 
for a long time as the "oriental eyeworm" because of its occurrence in Far Eastern Countries [32], has become established in Europe [33]. Indeed, following the first description in dogs, cats and foxes in Italy $[34,35]$ the infection has been increasingly reported in France, Switzerland, Spain, and Portugal [33] and recently in countries of the Balkans [36].

Human cases (in Europe still sparse) occur predominantly in children and elderly people and are associated with poor, rural communities and contexts of low health and socio-economic standards, where heavily infected dogs and cats live in close contact with humans [37-39]. High parasitic burdens cause various symptoms in humans such as conjunctivitis, lachrymation, corneal ulcers, rarely perforation of the cornea and even blindness [40]. In China, 84 cases of human thelaziasis were reported by the end of the 1970s and 700 additional cases between 1980 and 2006, which illustrates a rapid increase in its prevalence, although an increase in its reporting may play a role [37]. The host range of this nematode is wide as it parasitizes the eyes of dogs, cats, beech martens, foxes, wolves, rabbits, hares and humans [31]. Racoon dog (Nyctereutes procyonoides), a host species known from the Russian Far East [41], gained its importance as an invasive species in Europe. For a long time it was suspected that, like Thelazia species parasitizing cattle or horses (e.g., Thelazia gulosa, Thelazia lacrimalis, Thelazia rhodesi, Thelazia skrjabini), T. callipaeda has been transmitted by calyptrate flies (predominantly females) of the families Muscidae and Fanniidae to receptive animals due to their ability to suck perspiration, conjunctival liquid and exudates of their hosts. However, laboratory and field studies indicated that Musca domestica is not a vector of $T$. callipaeda under experimental or natural conditions [42]. The role of Amiota nagatai Okada, Phortica magna (Okada) and P. okadai (Máca) as vectors of T. callipaeda was first suggested in Japan [43,44]. In an independent study, the life cycle of $T$. callipaeda was investigated under experimental conditions in easternmost Russia [45]; the suspected vector $P$. variegata has never been confirmed later on in this area. The vectorial role of $P$. variegata (Fallén) was conclusively demonstrated under field and experimental conditions in Europe $[46,47]$ and that of P. okadai (Máca) in China [48]. In addition, P. kappa (Máca, 1977) was found to harbour T. callipaeda second stage larvae [49]. Thus, the range of vectors of $T$. callipaeda is apparently limited (see above), although probably wider than the few ascertained species.

Those Phortica species, known to be associated with thelaziosis, belong to the subgenus Phortica s. str., which is widely occurring in the Palaearctic and Oriental Regions. According to the phylogenetic data on Phortica it can be argued that the coevolution of T. callipaeda with Phortica spp. did not begin earlier than 13.1-19.5 million years ago, when Phortica s. str. diverged from other clades of the genus (the time given with $95 \%$ probability) [23]. Lachryphagy, which apparently occurs more widely amongst the Steganinae, must have emerged prior to that event, or/and polyphyletically. Furthermore, the present vicariant distribution of $T$. callipaeda is likely due to parasitizing almost or completely vicariant European (P. variegata) and East Asian species (P. magna, P. kappa, P. okadai) of Phortica s. str. and this should be preceded by its preglacial and/or interglacial continuous Eurasian distribution. This discontinuous distribution resulted in the occurrence of a single haplotype of T. callipaeda, thus far, in Europe in spite of testing specimens of various European countries and as many as eight host species (e.g., dogs, cats, beech martens, foxes, wolves, rabbits, hares and humans), in contrast to the eight haplotypes found in different Far Eastern countries [50]. The low genetic variability of $T$. callipaeda in Europe seems to be in accordance with only $P$. variegata as a confirmed vector, whilst at least four species of Steganinae have been suggested to act as vectors of the eight haplotypes of this nematode found in Asian countries. This finding ultimately supports a tight affiliation of $T$. callipaeda with the ecology of the intermediate hosts.

\section{Distribution and host affiliation of Thelazia callipaeda}

The distribution of $P$. variegata, the (main) European vector of $T$. callipaeda, is not known in sufficient detail for some countries [10]. Based on the ranges of temperature (i.e., $20-25^{\circ} \mathrm{C}$ ) and relative humidity (50-75\%) optimal for Phortica flies, as well as on the natural niche of this insect, a desktop implementation of the Genetic Algorithm for Rule-Set Prediction anticipated that large areas of Europe were likely to represent suitable habitats for P. variegata, therefore suggesting a potential expansion of thelaziosis [24]. Less than 10 years after this predictive niche model was published, $T$. callipaeda has been found in many areas of Europe predicted by the model [51-53]. Geographically, the prevalence of thelaziasis in different regions varies considerably in animals and humans, with most cases being recorded from the temperate to subtropical zones of the Old World, albeit in Europe only eight cases have been recorded in humans to date [33]. Case reports of human thelaziosis are much more frequent in Japan (southern part, mostly on Kyushyu island) with about 100 cases [54,55], South Korea ( $\mathrm{n}=24$ cases) [55], China (about 800 cases), especially the Shandong, Hebei, Anhui and Jiansu provinces where about half of all known human cases ( $n=$ about 450) were reported [37]. The low prevalence of human thelaziosis in the Russian Far East $(n=2)$ may show that this region, like northern Japan, lies close to the limits of the occurrence of $T$. callipaeda, although fox farming boosted its prevalence in animals $[45,56]$.

Interestingly, the majority of the Phortica s. str. species occur in the tropics of the Oriental Region, notwithstanding 
that data from India is sparse, most likely due to sparse use of appropriate collection methods (i.e., canopy traps). Indeed, sixty-three species of Phortica s. str. are known to be exclusively Oriental, six species are common to the Palaearctic and Oriental Regions, eight are exclusively Palaearctic and four are offshoots to other zoogeographical regions [57]. On the contrary, records of T. callipaeda from the Oriental region are sparse, with the exception of densely populated southern China, where up to 50 cases of human thelaziosis are known [37], including one case in Taiwan [58]. Cases of human thelaziosis from other countries of the Oriental Region come from India and Bangladesh $(\mathrm{n}=10)$, Indonesia $(\mathrm{n}=1)$, and Thailand (n=5) $[55,59,60]$. The sporadic occurrence of $T$. callipaeda is well illustrated in Thailand by H. Bänziger, who anecdotally mentioned capturing 172 individuals of at least 31 species of lachryphagous drosophilids (including a few females) sucking on his eyes; in spite of that, he never mentioned any disorder of his eyes [2]. However, his collections were made in forest habitats where no or few potential hosts of $T$. callipaeda were present (Banziger, pers. comm.). As yet we do not even know the name of any of the Oriental species of Steganinae transmitting $T$. callipaeda. It should be investigated whether the Oriental species show lesser susceptibility to this nematode, or if environmental conditions of tropical humid biota represent a barrier to the perpetuation of this infection.

The host range of Phortica spp. is simplest in Europe, where virtually only $P$. variegata and $P$. semivirgo (and $P$. erinacea in the extreme southeast) are potential vectors of $T$. callipaeda, although just the first-mentioned species is a confirmed vector.

Vertical microdistribution (stratification) of the genera Phortica and Amiota is of epidemiological importance, considering that adult flies dwell predominantly in the tree canopies [61]. However, they fly much lower when patrolling along forest tracks and clearings, repeatedly approaching to contact objects of interest from various angles before landing on his eyes. According to $\mathrm{H}$. Bänziger (personal communication) contacts with human eyes last for 35-163 seconds. Both tree canopy animals, such as beech martens, and terrestrial ones (e.g., foxes, wolves) may be contacted by these flies and infected with $T$. callipaeda larvae, whereas this may not be the case of subterranean/nocturnal European badgers [31]. Indeed, tree canopies are not the exclusive niches, at least for Phortica spp; their captures in caves may indicate their facultative overwintering there $[24,62,63]$.

\section{Male lachryphagy: cherchez la femme?}

Explaining lachryphagy in insects is not easy, as specific studies of this type are lacking. Lachrymal fluids contain, with the exception of salts, a certain amount of proteins, which can be utilized by the insects [64]. Protein uptake in the insect groups, where females are lachryphagous (e.g., some Muscidae and Fanniidae), may be considered parallel to the haematophagous behaviour displayed by females of various Diptera (e.g., Culicidae, Simuliidae, Tabanidae) in supporting oogenesis. However, since the lachryphagy of Drosophilidae is mostly associated with males [18], this could represent the taking of nutrients to the females as a "wedding present" [2]. This hypothesis might be supported by the fact that in spite of the rather uniform morphology of Amiota and Phortica, they present highly varied and specialized male genitalia, a recently evolved characteristic (i.e., caenogenetic structure) in contrast to most other structural characters. Indeed, in the majority of Phortica species, and notably in Phortica s. str., the aedeagus is membranous and supported by a strongly recurved medial rod, which seems to exclude direct copulation. In the related groups such as Amiota and Cacoxenus s. str., the proper aedeagus is even lacking. The ejaculatory apodeme is rudimentary to absent in Phortica s. str., whereas the paraphyses are as long as up to the apex of the aedeagus and apically trilobed (Figure 4). All of these characters together suggest indirect copulation (using mostly paraphyses) through a spermatophore, which could be then absorbed into the inner genitalia of the female in the same way as in Drosophila [65]. Therefore, following metabolism, the surplus protein taken up by the males from tears, could create the protein spermatophore needed by the female for supporting oogenesis. Another observation corroborating the hypothesis above is that the ingestion of

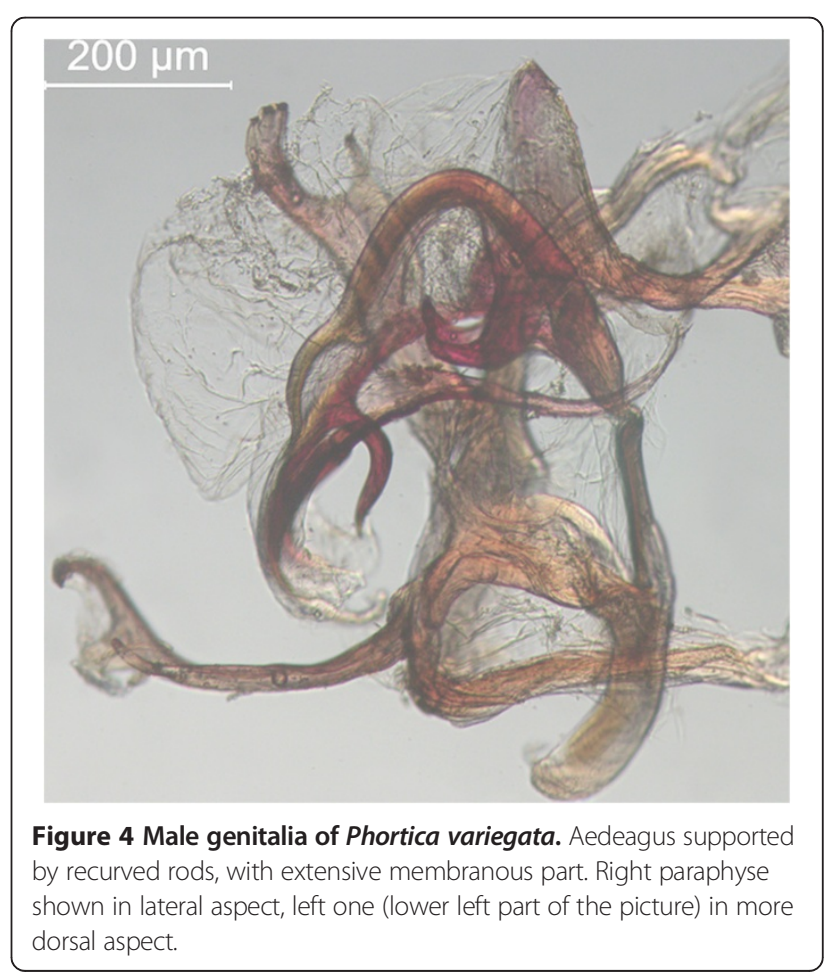


mammalian body fluids by males precedes copulation, which allows time for metabolism of these nutrients. Indeed, females are inactive in early spring, the first generation is thus protandric and the commonly occurring aggregations of males patrolling along forest clearings have apparently no relationship with swarming [24 and our own unpublished observations]. Thus, transfer of $T$. callipaeda seems to be, after all, a by-product of the gaining of nutrients for egg development (Figure 5), although more complicated than in the case of other Thelazia spp., where females are lachryphagous [66]. It is apparent that studies of the mating behaviour of lachryphagous Steganinae would be most rewarding, in these regards. Unfortunately, there is no information as to whether the intake of lachrymal fluid also signals for third-stage $T$. callipaeda larvae to leave its vector, or if the presence of developing nematodes boosts the lachryphagy, or if there is no such inter-relation. Moreover, it is likely that the passage of Thelazia larvae to the conjunctiva of the vertebrate host may be harmful to their vector fly, considering the mechanical stress by the relative large size of the parasite and the perforation of the proboscis labellae [45; Figure 6] and possible metabolic and/or physiologic changes they may induce. This may represent the extreme sacrifice of male Phortica in accomplishing their mission as vectors of the "oriental eyeworm". Still, reinfection may occur [45].

\section{Conclusions}

Undoubtedly, various aspects of the natural history of Steganinae need to be elucidated, mostly in relation to the extent of zoophagous behavior in various genera. Refined data on this taxon of drosophilids could prove useful to the biological control of phytophagous pests from the order Homoptera, as an alternative to chemical treatment. The rare experiments carried out in this field have

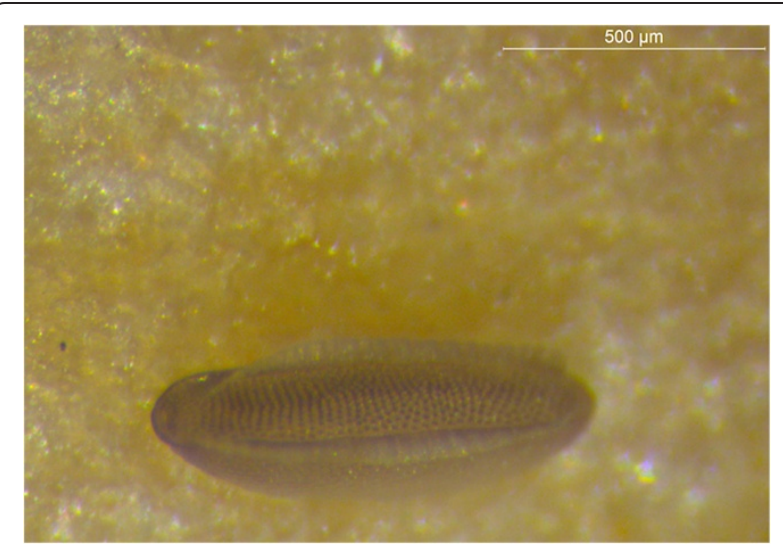

Figure 5 Phortica variegata, egg. Like in other Steganinae, the egg possesses a pair of longitudinal vela, as opposed to Drosophilinae which presents filamentous processes. Both serve to extend the surface of the egg and enhancing oxygen supply.

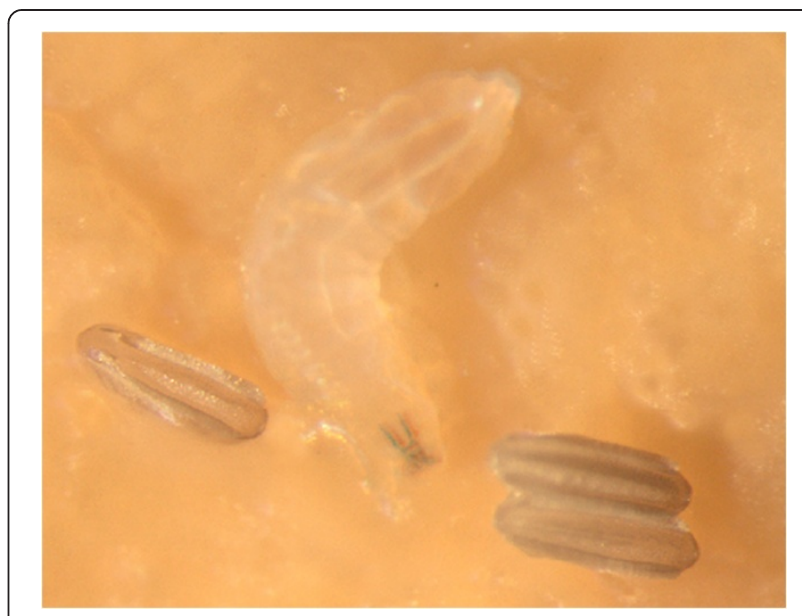

Figure 6 Phortica variegata, eggs and first instar larva. A rare picture of the artificial breeding of Phortica.

been referenced $[12,67]$. From a parasitological perspective, the reasons for the lachryphagy of adult insects remain yet to be elucidated, although the need for protein is most likely the main driver for this. Similarly, the possible role of sodium ions in this process also requires study.

Elucidation of the biology of lachryphagous drosophilids, including mating behavior, might also be addressed by rearing experiments (Figure 6). Indeed, although the rearing of $P$. variegata has been described, the results do not guarantee continual rearing [68]. Therefore, further protocols should be prepared or implemented in order to improve the rearing of Steganinae. Indeed, providing a larger space for rearing may facilitate the mating behaviour. In addition, since males are apparently protandric, and it is difficult to keep them alive whilst obtaining females, experiments with simultaneous rearing under different temperatures and light exposure may enable the study of seasonal rhythms and perhaps to align them. Although Phortica larvae have been found in fermenting tree sap [4], they may be virtually zoophagous as observed in P. xyleboriphaga [12]; fruit or other Drosophila breeding media do not seem suitable in supporting their development under laboratory conditions. Zoophagy in this genus is also suggested for $P$. (Sinophthalmus) picta (Coquillett) that lays either single eggs or numerous eggs for rapid propagation [69]. This egg-laying pattern might indicate parasitism and/or an adaptation for predation on gregarious prey. The possibility of larval zoophagy should be assessed by rearing Phortica (and allies) larvae together with those of other drosophilids (e.g. D. melanogaster). A better understanding of vector biology may assist not only in controlling the transmission of $T$. callipaeda, but also in discovering the origin of the predatory behaviour in this group of insects, thus leading to understanding the main drivers of their parasitism. Knowledge of the species composition 
of the vectors of T. callipaeda in Asia, mainly in its subtropical/tropical part, is still meagre. This should also be improved by implementing nematode detection in these flies as well as attempting experimental infections of various species of lacryphagous Steganinae.

\section{Additional file}

Additional file 1: Phortica variegata flying around human eyes. Description: This video shows the typical questing fly of Phortica variegata during a summer day in Basilicata region (southern Italy), an area highly endemic for Thelazia callipaeda. These insects are attracted by animal perspiration and ocular secretions.

\section{Competing interests}

The authors declare that they have no competing interests.

\section{Authors' contributions}

Both authors equally conceived this review article and equally contributed to writing it. Both read and approved the final version of the manuscript.

\section{Acknowledgement}

We greatly appreciate personal information communicated by Hans Bänziger (Chiang Mai, Thailand), Stéphane R. Prigent (Paris, France) and Hiró Takaoka (Oita, Japan). Thanks to Klavs Nielsen (Kobenhavn, Denmark), and R.P. Lia (The University of Bari, Italy) for some of the photographs used in the review. Bronwyn Campbell (The University of Bari, Italy) is acknowledged for her useful comments on the manuscript.

\section{Author details}

${ }^{1}$ Czech Entomological Society, Praha, Czech Republic. ${ }^{2}$ Department of Veterinary Medicine, University of Bari, 70010, Valenzano, Bari, Italy.

Received: 13 August 2014 Accepted: 2 November 2014

Published online: 18 November 2014

\section{References}

1. Russell RC, Otranto D, Wall RL: Encyclopedia of Medical \& Veterinary Entomology. Wallingford UK: CAB International; 2013:429. ISBN-13: 9781780640372.

2. Bänziger $H$, Boongird S, Sukumalanand $P$, Bänziger S: Bees (Hymenoptera: Apidae) that drink human tears. J Kansas Entomol Soc 2009, 82:135-150.

3. Ashburner M, Golic KG, Hawley RS: Drosophila. A Laboratory Handbook. New York: Cold Spring Harbor Lab Press; 2005.

4. Okada T: Systematic Study of the Early Stages of Drosophilidae. Tokio: Bunka Zugeisha Co; 1968

5. Michan L, Sortibran AC, Rodriguez-Arnaiz R, Ayala FJ: Global Drosophila Research: a bibliometric analysis. Dros Inf Serv 2010, 93:232-243.

6. Martin CA, Krantz DE: Drosophila melanogaster as a genetic model system to study neurotransmitter transporters. Neurochem Int 2014, 73:71-88.

7. van der Voet M, Nijhof B, Oortveld MA, Schenck A: Drosophila models of early onset cognitive disorders and their clinical applications. Neurosci Biobehav Rev, in press

8. Smith WW, Thomas J, Liu J, Li T, Moran TH. From fat fruit fly to human obesity. Physiol Behav, in press

9. Ntziachristos P, Lim JS, Sage J, Aifantis I: From fly wings to targeted cancer therapies: a centennial for notch signalling. Cancer Cell 2014, 25:318-334.

10. Bächli G: TaxoDros. The database on Taxonomy of Drosophilidae. 2014 Database 2014/01. [http://taxodros.uzh.ch/]

11. Brake I, Bächli G: Drosophilidae (Diptera). World catalogue of insects. Apollo Books, Stenstrup; 2008

12. Ashburner M: Entomophagous and other bizarre Drosophilidae. In The Genetics and Biology of Drosophila Vol. 3a. Edited by Ashburner M, Carson HL, Thompson JN, Ashburner M, Carson HL, Thompson JN. London: Academic Press; 1981:395-429.

13. Grimaldi DA: A phylogenetic, revised classification of the genera in the Drosophilidae (Diptera). Bull Am Mus Natural History (New York) 1990, 197:1-139.
14. Yassin A: Phylogenetic classification of the Drosophilidae Rondani (Diptera): the role of morphology in the postgenomic era. Syst Entomol 2013, 38:349-364.

15. Baer W: Ueber Stegana curvipennis Fall. Naturwiss Z für Forst und Landwirtsch (Stuttgart) 1914, 12:379.

16. Máca J: Octomilkovití (Diptera: Drosophilidae Jizerských hor a Frýdlantska. Drosophilidae (Diptera) of the Jizerské hory Mts and Frýdlant region (northern Bohemia, Czech Republic). Sborník Severočeského Muzea, Prírodní Vědy Acta Musei Bohemiae Borealis, Scientiae Naturales 2009, 27:173-184.

17. Schiner JR: Catalogus Systematicus Dipterorum Europae. Vindobona: Societas zoologico-botanica; 1864.

18. Máca J: Revision of Palearctic species of Amiota subg. Phortica (Diptera, Drosophilidae). Acta Ent Bohemoslov 1977, 74:114-130.

19. Kozlov DP: Perviy sluchai obnaruzhenia Thelazia callipaeda Railliet et Henry, 1910 u cheloveka na teritorii SSSR. [First discovery of Thelazia callipaeda Railliet et Henry, 1910 in a human on the teritory of USSR]. Akademia Nauk SSSR Trudy gelmintologicheskoi laboratorii (Moskva) 1963, 13:75-77.

20. Otranto D, Stevens JR, Testini G, Cantacessi C, Máca J: Molecular characterization and phylogenesis of Steganinae (Diptera, Drosophilidae) inferred by the mitochondrial cytochrome $c$ oxidase subunit 1. Med Vet Entomol 2008, 22:37-47.

21. Chen HW, Toda MJ: A revision of the Asian and European species in the subgenus Amiota Loew (Diptera, Drosophilidae) and the establishment of species-groups based on phylogenetic analysis. J Nat Hist 2001, 35:1517-1563.

22. Máca J: Taxonomic notes to the genera previously classified in the genus Amiota Loew (Diptera: Drosophilidae, Steganinae). Acta Universitatis Carolinae, Biol 2003, 47:247-274

23. Cao HL, Wang XL, Gao JJ, Prigent SR, Watabe H, Zhang YP, Chen HW: Phylogeny of the African and Asian Phortica (Drosophilidae) deduced from nuclear and mitochondrial DNA sequences. Mol Phylogenet Evol 2011, 61:677-685.

24. Otranto D, Brianti E, Cantacessi C, Lia RP, Máca J: The zoophilic fruitfly Phortica variegata: morphology, ecology and biological niche. Med Vet Entomol 2006, 20:358-364.

25. Yuval B: Mating systems of blood-feeding flies. Ann Rev Entomol 2006, 51:413-440.

26. Bächli G, Vilela CR, Andersson Escher SA, Saura A: The Drosophilidae (Diptera) of Fennoscandia and Denmark. Fauna Entomologica Scandinavica, Volume 39. Leiden: Brill; 2004.

27. Okada T: Systematic Study of Drosophilidae and Allied Families of Japan. Tokyo: Gihodo Co; 1956.

28. Smith RL: The trouble with bobos, Paraleucopis mexicana Steyskal, at Kino bay, Sonora, Mexico (Diptera, Chamaemyiidae). Proc Ent Soc Washington 1981, 83:406-412.

29. Bänziger H: Skin-piercing blood-sucking moths III: Feeding act and piercing mechanism of Calyptra eustrigata (Hmps.) (Lep., Noctuidae). Mitt Schweiz Ent Ges 1980, 53:127-142.

30. Zaspel JM, Zahiri R, Hoy MA, Janzen D, Weller SJ, Wahlberg N: A molecular phylogenetic analysis of the vampire moths and their fruit-piercing relatives (Lepidoptera: Erebidae: Calpinae). Mol Phylogenet Evol 2012, 65:786-791.

31. Otranto D, Dantas-Torres F, Mallia E, DiGeronimo PM, Brianti E, Testini G, Traversa D, Lia RP: Thelazia callipaeda (Spirurida, Thelaziidae) in wild animals: Report of new host species and ecological implications. Vet Parasitol 2009, 166:262-267.

32. Anderson RC: Nematode Parasites of Vertebrates. Their Development and Transmission. Wallingford, UK: CABI Publishing; 2000.

33. Otranto D, Dantas-Torres F, Brianti E, Traversa D, Petrić D, Genchi C, Capelli G: Vector-borne helminths of dogs and humans in Europe. Parasit Vectors 2013, 6:16

34. Rossi L, Bertaglia P: Presence of Thelazia callipaeda Railliet and Henry, 1910, in Piedmont, Italy. Parassitologia 1989, 31:167-172.

35. Otranto D, Ferroglio E, Lia RP, Traversa D, Rossi L: Current status and epidemiological observation of Thelazia callipaeda (Spirurida, Thelaziidae) in dogs, cats and foxes in Italy: a "coincidence" or a parasitic disease of the Old Continent? Vet Parasitol 2003, 116:315-325.

36. Hodzic A, Latrofa MS, Annoscia G, Alic A, Beck R, Lia RP, Dantas-Torres F, Otranto D: The spread of zoonotic Thelazia callipaeda in the Balkan area. Parasit Vectors 2014, 7:328.

37. Shen JL, Gasser RB, Chu DY, Wang ZX, Yuan XS, Cantacessi C, Otranto D: Human thelaziosis - a neglected parasitic disease of the eye. J Parasitol 2006, 92:872-875 
38. Otranto D, Dutto M: Human thelaziasis, Europe. Emerg Infect Dis 2008 , 14:647-649

39. Fuentes I, Montes I, Saugar JM, Gárate T, Otranto D: Thelaziosis, a zoonotic infection, Spain, 2012. Emerg Infect Dis 2012, 18:2073-2075.

40. Otranto D, Eberhard ML: Zoonotic helminths affecting the human eye. Parasit Vectors 2011, 23:41.

41. Kozlov DP: Izuchenie biologii Thelazia callipaeda Railliet et Henry, 1910 [Study of the biology of Thelazia callipaeda Railliet et Henry, 1910]. Akademia Nauk SSSR Trudy gelmintologicheskoi laboratorii (Moskva) 1963, 13:330-346.

42. Otranto D, Lia RP, Testini G, Milillo P, Shen JL, Wang ZX: Musca domestica is not a vector of Thelazia callipaeda in experimental or natural conditions. Med Vet Entomol 2005, 19:135-139.

43. Nagata Y: [The discovery of eye-worm, Thelazia callipaeda, VIII]. Jap J Vet Sci 1959, 21:103.

44. Nagata Y: [The discovery of eye-worm, Thelazia callipaeda, IX-X]. Jap J Vet Sci 1960, 22:475.

45. Kozlov DP: Raschifrovka tsikla razvitia nematody Thelazia callipaeda parazita glaza cheloveka i plotoiadnykh mlekopitaiushikh [The life cycle of nematode Thelazia callipaeda parasitic in the eye of the man and carnivores]. Dokl Akad Nauk SSSR 1962, 142:732-733.

46. Otranto D, Lia RP, Cantacessi C, Testini G, Troccoli A, Shen JL, Wang ZX: Nematode biology and larval development of Thelazia callipaeda (Spirurida, Thelaziidae) in the drosophilid intermediate host in Europe and China. Parasitology 2005, 131:847-855.

47. Otranto D, Cantacessi C, Testini G, Lia RP: Phortica variegata is an intermediate host of Thelazia callipaeda under natural conditions: evidence for pathogen transmission by a male arthropod vector. Int $\mathrm{J}$ Parasitol 2006, 36:1167-1173.

48. Wang ZX, Hu Y, Wang KC, Wang HY, Jiang BL, Zhao P, Wang ZC, Ding W, Wang F, Xia XF: Longitudinal investigation and experimental studies on thelaziasis and the intermediate host of Thelazia callipaeda in Guanhua county of Hubei province. Chin J Epidemiol 2003, 24:588-590

49. Aoki C, Otsuka Y, Takaoka H, Hayashi T: [Natural infections of three Amiota species with larvae of Thelazia in Oita]. Med Entomol Zool 2003, 54:52.

50. Otranto D, Testini G, De Luca F, Hu M, Shamsi S, Gasser RB: Analysis of genetic variability within Thelazia callipaeda (Nematoda: Thelazioidea) from Europe and Asia by sequencing and mutation scanning of the mitochondrial cytochrome $c$ oxidase subunit 1 gene. Mol Cell Probes 2005, 19:306-313.

51. Malacrida F, Hegglin D, Bacciarini L, Otranto D, Nägeli F, Nägeli C, Bernasconi C, Scheu U, Balli A, Marenco M, Togni L, Deplazes P, Schnyder M: Emergence of canine ocular thelaziosis caused by Thelazia callipaeda in southern Switzerland. Vet Parasitol 2008, 157:321-327.

52. Miró G, Montoya A, Hernández L, Dado D, Vázquez MV, Benito M, Villagrasa M, Brianti E, Otranto D: Thelazia callipaeda: infection in dogs: a new parasite for Spain. Parasit Vectors 2011, 4:148.

53. Vieira L, Rodrigues FT, Costa A, Diz-Lopes D, Machado J, Coutinho T, Tuna J, Latrofa MS, Cardoso L, Otranto D: First report of canine ocular thelaziosis by Thelazia callipaeda in Portugal. Parasit Vectors 2012, 21:124.

54. Kamakura K, Kamakura S, Tamura S, Shiomi C, Nobukiyo A, Furukawa T: Incidence of parasitosis associated with Oriental eye worm (Thelazia callipaeda) in dogs and cats in Hiroshima Prefecture. The Hiroshima J Vet Med 1998, 13:63-68.

55. Koyama Y, Ohira A, Kono T, Yoneyama T, Shiwaku K: Five cases of thelaziasis. Br J Ophthalmol 2000, 84:441.

56. Miroshnichenko VA, Desiaterik MP, Novik AP, Gorbach TV, Papernova HI: Sluchai teliaziosa glaz u rebionka v vozraste 3 let. [Case of the eye thelaziosis in the 3years old child]. Vestn Oftalmol 1988, 104:64.

57. Chen HW, Máca J: Ten new species of the genus Phortica from the Afrotropical and Oriental regions (Diptera: Drosophilidae). Zootaxa 2012, 3478:493-509.

58. Cheung WK, Lu HJ, Liang CH, Peng ML, Lee HH: Conjunctivitis caused by Thelazia callipaeda infestation in a woman. J Formos Med Assoc (Taipei) 1998, 97:425-427.

59. Akhanda AH, Akonjee AR, Hossain MM, Rahman MA, Mishu FA, Hasan MF, Akhanda TH: Thelazia callipaeda infestation in Bangladesh: a case report Mymensingh Med J 2013, 22(3):581-584

60. Handique AK, Khan AM, Tamuli A: Ocular thelaziasis in a 7-month-old infant. Indian J Med Microbiol 2014, 32:84-86.
61. Toda MJ: Vertical microdistribution of Drosophilidae (Diptera) within various forests in Hokkaido III. The Tomakomai Experiment Forest, Hokkaido University. Res Bull Coll Exp Forests, Faculty of Agric Hokkaido University 1987, 44:611-632.

62. Beschovsky VL: Representatives of Diptera - Brachycera in the caves of Bulgaria. Académie Bulgare des Sci Bulletin de l'Institut de Zool et Musée 1972, 35:23-29.

63. Bächli G, Weber D: Taufliegen oder Kleine Fruchtfliegen (Insecta, Diptera, Drosophilidae) aus Höhlen des Grossherzogtums Luxemburg. Ferrantia 2013, 69:349-353.

64. Rauen HM: Biochemisches Taschenbuch. 2. Teil. Berlin: Springer; 1964.

65. Alonso-Pimentel H, Tolbert LP, Heed WB: Ultrastructural examination of the insemination reaction in Drosophila. Cell Tissue Res 1994, 275:467-479.

66. Otranto D, Stevens JR, Cantacessi C, Gasser RB: Parasite transmission by insects: a female affair? Trends Parasitol 2008, 24:116-120.

67. Arzone A: Acletoxenus formosus (Loew) (Diptera Drosophilidae) predatore di Trialeurodes vaporariorum (Westwood). Boll Zool agr bachic, Ser II, Milano 1998, 30:55-59

68. Otranto D, Cantacessi C, Lia RP, Grunwald Kadow IC, Purayil SK, Dantas-Torres F, Máca J: First laboratory culture of Phortica variegata (Diptera, Steganinae), a vector of Thelazia callipaeda. J Vector Ecol 2012, 37:458-461.

69. Wheeler MR: The Drosophilidae of the Nearctic Region exclusive of the genus Drosophila. Univ Tex Publ (Austin) 1952, 5204:162-218.

doi:10.1186/s13071-014-0516-4

Cite this article as: Máca and Otranto: Drosophilidae feeding on animals and the inherent mystery of their parasitism. Parasites \& Vectors 2014 7:516.

\section{Submit your next manuscript to BioMed Central and take full advantage of:}

- Convenient online submission

- Thorough peer review

- No space constraints or color figure charges

- Immediate publication on acceptance

- Inclusion in PubMed, CAS, Scopus and Google Scholar

- Research which is freely available for redistribution 